University of Nebraska - Lincoln

DigitalCommons@University of Nebraska - Lincoln

Faculty Publications, Department of Psychology

Psychology, Department of

October 1991

\title{
Cognitive Processes and Prosocial Behaviors Among Children: The Role of Affective Attributions and Reconciliations
}

\author{
Gustavo Carlo \\ University of Nebraska-Lincoln, carlog@missouri.edu \\ George Knight \\ Arizona State University, george.knight@asu.edu \\ Nancy Eisenberg \\ Arizona State University, nancy.eisenberg@asu.edu \\ Ken J. Rotenberg \\ Lakehead University, k.j.rotenberg@keele.ac.uk
}

Follow this and additional works at: https://digitalcommons.unl.edu/psychfacpub

Part of the Psychiatry and Psychology Commons

Carlo, Gustavo; Knight, George; Eisenberg, Nancy; and Rotenberg, Ken J., "Cognitive Processes and Prosocial Behaviors Among Children: The Role of Affective Attributions and Reconciliations" (1991). Faculty Publications, Department of Psychology. 152.

https://digitalcommons.unl.edu/psychfacpub/152

This Article is brought to you for free and open access by the Psychology, Department of at DigitalCommons@University of Nebraska - Lincoln. It has been accepted for inclusion in Faculty Publications, Department of Psychology by an authorized administrator of DigitalCommons@University of Nebraska - Lincoln. 
Published in Developmental Psychology 27:3 (1991), pp. 456-461. Copyright (C) 1991 by the American Psychological Association, Inc. Used by permission.

"This article may not exactly replicate the final version published in the APA journal. It is not the copy of record." http://www.apa.org/journals/dev/

\title{
Cognitive Processes and Prosocial Behaviors Among Children: The Role of Affective Attributions and Reconciliations
}

\author{
Gustavo Carlo, George P. Knight, and Nancy Eisenberg \\ Arizona State University \\ Ken J. Rotenberg \\ Lakehead University, Thunder Bay, Ontario, Canada
}

\begin{abstract}
Although attributions about others' sad emotions have been shown to be positively related to helping behavior, there have been considerable inconsistencies in the findings. This study was designed to investigate the relations of affective attributions, affective reconciliations, and cognitive perspective-taking measures to prosocial behavior. Eightynine preschool through second grade children were administered various social cognition indices (two affective and one cognitive); the children were then given an opportunity to help a same-sex confederate child obtain toys. Helping that required a specific form of affective attribution and reconciliation was significantly related to the affective attribution and reconciliation measures when the demands required by the helping opportunity "matched" the social cognition measure demands. The findings are discussed in terms of the need to reconceptualize the relations between social cognitive skills and helping.
\end{abstract}

This research was sponsored by a grant to George P. Knight from the Office of the Vice President of Research at Arizona State University and by Career Development Award K04HD00717 from the National Institute of Child Health and Development and National Science Foundation Grant BNS-8807784 awarded to Nancy Eisenberg. We wish to thank the principals, staff, and teachers of Hudson, Evans, and Laird Elementary Schools, and the Child Study Lab at Arizona State University for their cooperation. We also gratefully acknowledge the help of Jolyn Askey, Sandy Burke, Roxana Carlo, Lisa Gambino, Sarette Horowitz, Chris Knight, Beverly Matsumoto, Dan Milburn, Kevin Mohler, Mark Morris, Jane Russo, Kristen Schillereff, and Greta Thies.

Developmental researchers have frequently theorized about and investigated the possible cognitive antecedents of prosocial behaviors. One such antecedent is perspective taking, the ability or tendency to differentiate another's view from one's own. Measures of perspective taking have assessed the individual's evaluation of the perceptual, cognitive, and affective cues that differentiate between others and self as well as the tendency or ability to shift or achieve balance between those cues (Shantz, 1975). Thus, perspective taking has been conceptualized as a global skill, so that, in general, higher levels of perspective taking have been expected to be associated with prosocial behavior.

Despite these theoretically based expectations, the observed empirical relations between perspective taking and prosocial behaviors have been relatively inconsistent (Eisenberg, 1986; Iannotti, 1985; Kurdek, 1978; Underwood \& Moore, 1982), even though a significant low positive association has been demonstrated using meta-analytic procedures (Underwood \& Moore, 1982). The only empirical investigations that have examined the cause of these inconsistencies (Denham, 1986; Iannotti, 1985) involved a battery-of-measures approach. For example, Denham (1986) found a positive relation between an aggregate measure of helping and an aggregate measure of affective perspective taking, whereas Iannotti (1985) found a positive relation between an aggregate prosocial behavior measure and an affective perspective-taking measure. Thus, on the basis of these findings, these researchers concluded that affective perspective taking is a precursor to helping behaviors.
Another potential explanation for the inconsistent findings is that perspective-taking measures sometimes may not have tapped cognitive abilities relevant to the prosocial behavior being assessed. If this were true, the pattern of relations across studies would be expected to vary as a function of the relevance of the perspective-taking measure used.

This investigation is based on the proposition that there are different types of sociocognitive skills and that a measure of a specific sociocognitive skill will be consistently related to a prosocial behavior only if that behavior requires that specific type of social cognition. Thus, attributions and reasoning about others' emotions would be expected to result in prosocial behavior only to the extent that the behavior in question would be expected to be facilitated by an understanding of the relevant affective cues or process (Eisenberg, 1986). For example, attributions about another's affective state may be associated with helping in a situation that requires processing of affective cues, such as when a needy other looks sad or is in distress. Similarly reasoning about inconsistent cues related to affect (e.g., contradictory facial and situational cues) may be associated with helping in situations that require reconciling such inconsistencies, such as when a needy other does not display sad facial affect. In contrast, cognitive perspective-taking measures that require an awareness that another's knowledge may differ from one's own (e.g., Flavell, Botkin, Fry, Wright, \& Jarvis, 1968, cartoon story task) may not be associated with helping in situations involving overt affective cues because these measures do not require coordinating affective cues. 
Recently, researchers have begun to focus on subtle differences in the cognitive demands of various social cognition measures (e.g., Gnepp, 1983; Hoffner \& Badzinski, 1989; Saarni, 1979). Using picture-story measures in which sad or happy facial and situational cues are depicted, investigators have examined young children's abilities to identify affective cues and to reconcile conflicting affective cues. These investigators have found that young children preferentially attend to facial cues, that there is increasing attention to situational cues with age, and that the accuracy of report of both positively and negatively valenced cues increases with age (e.g., Iannotti, 1978; Kurdek \& Rogdon, 1975; Shantz, 1975). There is also evidence that young children can attend to both facial and situational affective cues and that this ability and the ability to reconcile incongruent cues increases with age (e.g., Gnepp, 1983; Gnepp, McKee, \& Domanic, 1987; Reichenbach \& Masters, 1983; Saarni, 1979).

The ability to infer others' emotional states has traditionally been considered to be a prerequisite to empathy as well as a facilitator of some types of prosocial responding, such as altruism (Eisenberg \& Miller, 1987; Hoffman, 1984; Shantz, 1975). However, in a situation in which the cues indicating a need for help are vague or apparently conflicting (e.g., when one is not sure whether someone wants or needs help, perhaps because of an incongruence between the situation and the other's facial expression), children may help only if they are capable of reconciling the incongruent cues. In contrast, in a situation in which the facial and situational cues are congruent and salient, children's helping may vary as a function of their ability to accurately interpret another's sad cues. Furthermore, individual and group differences in attributions and reasoning about others' affective states could account for individual and group differences in helping when such behavior specifically requires a specific type of attribution or reasoning about others' affects.

The measures of social cognition and prosocial behavior used in this study were selected so that the type of social cognition assessed matched the sociocognitive processing required by the prosocial behavior in which children could engage (Eisenberg, 1986; Kurdek, 1978). Attributions of sadness in situations with congruent sad facial and sad situational cues were expected to be positively related to helping in a similar context. Similarly, reconciliations about affect in a context in which the facial and situational cues were incongruent or conflicting (i.e., one type of cue was positive, whereas the other was negative) were expected to be associated with helping in a similar context. Finally, children's responses to a cognitive perspective-taking task that did not focus on the processing of facial and situational affective cues were not expected to be significantly correlated with helping in the above-mentioned contexts.

\section{Method}

\section{Subjects}

Participants were 89 preschool through second grade children (mean age $=81.1$ months, $S D=16.7$ ). Because social cognition skills are believed to undergo a qualitative transformation around seven years of age (Shantz, 1975) and to ease interpretation of the results, children were grouped into two age groups: up to 7 years of age and 7 years of age or older. Mean ages of the older and young groups were 96.4 and 68.7 months, respectively. There were 20 older boys, 20 older girls, 30 young boys, and 19 young girls. The participants attended a child study laboratory/day-care center or one of two elementary schools in a middle-class community in the same general area as the day care center.

\section{Apparatus and Materials}

The experimental room contained a color monitor on a table, two chairs facing the table, and a one-way mirror; under the mirror was a crank handle attached to a box on the wall. The child was videotaped through the one-way mirror during the administration of the social cognition tasks and during the helping task.

Affective attribution and reasoning task. The affective attribution and reasoning task (adapted slightly from Iannotti, 1978) consisted of 12 randomly ordered black and white photographs mounted on paper (the sex of the child in the picture was matched to the sex of the participant) and corresponding stories. There were six congruent stories (two sad, two happy, one angry, and one afraid) in which the facial expression and the situational cues in the story were consistent (e.g., both cues were sad or both cues were happy). In addition, there were six incongruent stories (four that included mixed sad and happy cues and two that included mixed angry and afraid cues) in which the facial expression and the situational cues were conflicting (e.g., there were two stories with a happy face in a sad situation and two stories with a sad face in a happy situation).

A choice sheet (one set for each sex) displaying line drawings of eight facial expressions was used to assess affective attributions. There were four pairs of faces randomly ordered on the sheet. The paired faces portrayed happy-very happy, sad-very sad, angry-very angry, and afraid-very afraid affective expressions. In addition, there was one neutral facial expression (labeled "nothing at all"). Before presenting the stories and after each story, the experimenter pointed to each of the faces on the choice sheet and labeled each one. After the third example, the experimenter discontinued labeling if it was clear that the child understood the faces.

For each story, the picture depicting the events in the short story was covered with a sheet of paper as the experimenter read the story. The picture was revealed at a prompt (as designed by Iannotti, 1978) during the middle of the story. The children were then asked to indicate how they felt, how the character in the story felt (affect attribution), and how they knew the protagonist felt that way (affect reasoning). The children were required to indicate their choice on the facial choice sheet by pointing, even if they verbalized the emotions to the first two questions. The third question required a verbal response. ${ }^{1}$

Cognitive perspective-taking task. The stimulus materials for the cognitive perspective-taking task consisted of seven color drawings that depicted a story. With these cards (see Flavell et al., 1968, Task ID), children were told the story of a boy who was chased by a dog, ran away from the dog, saw an apple tree, climbed up the tree until the dog went away and started eating an apple. They

${ }^{1}$ The affective match between the children's reported affect and that of the story protagonist (using both the first and the second questions that were asked; Iannotti, 1978) was also coded. Results indicated no significant zero-order or partial correlations (controlling for both age and sex simultaneously) between empathic-like responses and helping in either of the two conditions; $r$ s ranged from -.23 to .22 , except that matching sad affect in the congruent picture stories was positively related to helping in the congruent helping condition, $r=.39, p<.05$, when both age and sex were partialed out. However, some researchers have seriously questioned whether picture-story-type measures are valid indicators of empathy (Eisenberg \& Lennon, 1983; Eisenberg \& Miller, 1987; Strayer \& Schroeder, 1989). 
were asked to repeat the story back to the experimenter to ensure understanding. If children failed to indicate the purpose of the dog during his or her narration, he or she was asked why the boy climbed the tree and what the dog was doing in the picture that depicted the boy in the tree and the dog leaving (second to last picture). Next, the children were told that they were going to show an imagined friend four pictures (out of the seven) that did not show the dog chasing the boy up the tree. The children were asked what story they thought their friend would tell. If a child failed to spontaneously mention that the dog had chased the boy, the experimenter asked why their friend would think the boy climbed the tree and why their friend would think the dog was there. The children were assumed to be taking the imaginary peer's perspective if they realized that their peer would not know that the dog chased the boy up the tree (as was the case in the longer version of the story). This measure was deemed to be an index of a social cognition skill that was irrelevant to helping in our experimental context because this task did not concern the relation between facial and situational affective cues.

\section{Procedure and Helping Task}

After a same-sex experimenter administered the affective attribution and reasoning task and the cognitive perspective-taking task in a counterbalanced order, the children were given an opportunity to help another child. Experimenters were unaware of the hypotheses of the study, unaware of how the social cognition measures were to be scored, and unaware of the condition to which the child had been assigned until they were presented with the helping task. Children were assigned (counterbalanced) to one of two helping conditions (see condition description below). All children were allowed to turn the crank attached to the wall, to show how hard it was to turn. The children then viewed a 4 min videotape showing a same-sex (male model's age $=57$ months; female model's age $=60$ months) confederate (Johnnie or Susie). The confederate child wore a plaster hand cast that reached to his or her elbow. He or she was shown walking to a crank with a same-sex adult. The adult then left and the confederate child began turning the crank (from this point on, only the confederate's head, shoulders and moving arms could be seen).

All children were told that the confederate child on the TV was in another room at the same time and that the confederate child was going to turn a crank similar to the one in the subject's room. The children were told that the confederate child was from another class just like theirs, that he or she was turning the crank to get some toys, and that the faster the crank was turned, the more toys the confederate child would receive. Children were told that if they turned the crank, it would make it easier for the confederate child to get more toys because it would make the crank turn faster (for similar tasks, see Liebert \& Baron, 1972; Mallick \& McCandless, 1966). The experimenter reiterated this information if necessary. The children were also told that they could see the confederate child on the TV but that the confederate could not see them. In the incongruent condition, the confederate in the film was smiling throughout the whole tape even though the crank was hard to turn. In the congruent condition, the confederate was frowning and looked frustrated. In both conditions, the confederate child paused and said (30 s into the film), "Boy, this is hard, especially with a broken hand", after which the experimenter said, "I guess that is hard, with a broken hand. Anyway, I have to get something, I'll be back in a couple of minutes. You can watch [Johnny/Susie] or you can turn the handle [the experimenter turned the handle a couple of times to lessen any inhibitions] or do whatever you want." The experimenter left the room and returned after $90 \mathrm{~s}$.

\section{Coding Procedure}

Affective attribution and reasoning task. Responses to only the happy and sad stories were coded because these were affectively relevant to the prosocial behavior. Furthermore, because the children seemed rarely to distinguish affective intensity in their responding, we collapsed their responses across the two affective levels. Separate scores were obtained for the congruent and incongruent stories. For the congruent stories, attributions were coded as I for reference to any sad (sad or very sad) or any happy (happy or very happy) affect if the attribution of how the character felt matched the affective cues in the story. All other responses were coded as 0 . Scores were summed across stories depicting the same affect (two happy and two sad stories), producing both sad and happy attribution scores. The total score for sad attributions $($ alpha $=.50)$ or happy attributions (alpha $=.37$ ) ranged from 0 to 2 (alphas of .50 or above are often considered adequate for 2- or 4-item scales, especially if the hypothesized relations are significant; Nunnally, 1967).

For the incongruent stories, reconciliations were coded as I for any happy or any sad attribution of how the character felt that acknowledged the incongruent affective cues and discounted one of those affective cues (e.g., "He's sad because he didn't get the birthday presents that he wanted" or "She's sad even though she's smiling:'). All other responses were coded as 0 . There were four possible reconciliation indices (using a specific sad or happy affect in combination with the facial or situational cue). However, because only $20 \%$ of the responses (out of 356 possible responses) were reconciliations and because some of the specific reconciliation indices occurred relatively infrequently, these indices were summed to derive a total reconciliation score (alpha $=.55$; total reconciliation scores ranged from 0 to 4 ). Codings of reconciliations were not appropriate for the congruent stories because these stories contained consistent facial and situational affective cues. Because reconciliations in the incongruent stories required that children indicate the story character's emotional state, attributions were not coded separately for these stories.

Interrater agreement on the $22 \%$ of the cases coded by two independent naive judges was $100 \%$ for attributions for the congruent stories and $91 \%$ for reconciliations for the incongruent stories. Disagreements were resolved by discussion.

Cognitive perspective-taking task. Responses to the cartoon story task were coded using an adaptation of the scoring procedures of Flavell et al. (1968). A score of 1 was assigned if (a) the subject did not spontaneously mention or indicate when probed that the dog played a role in the boy's climbing the tree and (b) no fear motive was mentioned. All other responses were scored as 0 . The correlation between responses coded according to this modified coding scheme and those coded according to Flavell et al.'s (1968) original coding scheme was significant, $r(84)=.79, p<.001$, two-tailed. Three subjects' scores could not be computed because of difficulty in hearing the videotapes. Interrater agreement was $92 \%$ on the $23 \%$ of the cases coded by two independent naive judges.

Helping task. In order to obtain a measure that reflected qualitative as well as quantitative dimensions of helping, three helping indices were coded separately from the videotapes by two independent naive judges. The two quantitative indices were the number of seconds the subject turned the crank and the number of revolutions of the crank. The qualitative index was a 7-point rating (from no effort to a lot of effort) of subjects' effort while they turned the crank. The interrater reliability on $22 \%$ of the cases was $100 \%$ agreement for the number of turns, $r=.99$ for time turning the handle and $r=.81$ for effort. Disagreements were resolved by discussion.

\section{Results}

Affective Attributions and Reconciliations and Cognitive Perspective Taking

Interrelations among the scores. Sad attribution scores in the congruent stories were unrelated to happy attribution 
scores in these stories, and both sad and happy attributions were unrelated to reconciliation scores in the incongruent stories, $r \mathrm{~s}(87)=-.01$ and .19 , both $n s$. respectively.

Correlational analyses also indicated that the cartoon story task was significantly related to sad attribution scores in the congruent stories, $r(84)=.29, p<.01$, two-tailed. However, this relation became nonsignificant when age was partialed out, $r=.18$. There were no other significant relations between the cartoon story task and the happy attribution or the reconciliation measures, $r \mathrm{~s}(84)=.01$ and $.12, n s$, respectively.

Age and gender differences. To assess age and gender differences in the attribution scores derived from the congruent stories, a 2 (age) $\times 2$ (sex) $\times 2$ (valence: happy; sad) unique sums-of-squares analysis of variance (ANOVA) with valence as a repeated factor was performed. There were significant main effects of age, $F(1,85)=11.81, p<.01$, and valence, $F(1,85)=19.77, p<.001$. Older children correctly reported sad and happy emotions combined $(M=3.83, S D=.39)$ more often than did young children $(M=3.37, S D=.73)$, and the children reported more happy $(M=1.94, S D=.23)$ than $\operatorname{sad}(M$ $=1.63, S D=.59)$ emotions. There also was a significant Age $\times$ Valence interaction, $F(1,85)=10.85, p<.01$. Tests of simple effects indicated that older children reported sad emotions more often than did young children, $F(1,85)=18.59, p<.001$ (for older children, $M=1.88, S D=.33$; for young children, $M$ $=1.43, S D=.68$ ), whereas there were no age differences for happy attributions. No other effects were significant.

To assess age and gender differences in the reconciliation scores derived from the incongruent stories, we performed an additional 2 (age) $\times 2$ (sex) unique sums-of-squares ANOVA. There were no significant effects, even though the older children did reconcile the incongruent cues somewhat more often than did the young children (for older children, $M=$ $2.13, S D=1.11$; for young children, $M=1.84, S D=1.21$ ). Similarly, a 2 (age) $\times 2$ (sex) unique sums-of-squares ANOVA was performed to assess age and gender differences on the cartoon story task. There was a significant main effect for age (for young children, $M=.09, S D=.29$; for older children, $M$ $=.40, S D=.50), F(1,82)=11.99, p<.001$, and a significant main effect for gender (for boys, $\mathrm{M}=.13, S D=.33$; for girls, $\mathrm{M}=.37, S D=.49), F(1,82)=6.33, p<.01$. Older children and girls scored higher on this type of social cognition.

\section{Helping Measure}

We performed a 2 (age) $\times 2($ sex $) \times 2$ (helping condition) multivariate analysis of variance (MANOVA) to assess the effects of age, sex, and helping condition on the number of turns, time turning, and effort indices. There was a significant multivariate main effect of age, $F(2,80)=3.11, p<.05$ (for older children, $M \mathrm{~s}=25.78,8.80$, and 4.15, $S D \mathrm{~s}=30.25,10.57$, and 2.44; for young children, $M \mathrm{~s}=37.27,8.67$, and $4.59, S D \mathrm{~s}$ $=33.37,10.13$, and 2.48, for time turning, number of turns, and effort, respectively). However, the univariate analyses were not significant. There were no other significant effects.

\section{Relations Between Helping and the Affective Attribution, Reconciliation. and Cognitive Perspective-Taking Scores}

The zero-order relations and the partial correlations (controlling for both sex and age) between helping and the attribution and reconciliation measures are presented in Table 1 (we computed one-tailed significance tests for the significant correlations because these relations were hypothesized a priori). To reduce the total number of possible correlations while still examining the hypothesized relations, we formed a composite index of helping. The composite was the sum of the standardized number of turns and the standardized number of seconds turning $(r=.80, p<.001$, between these two indices) multiplied by the effort score. Conceptually, this index weighed the amount of helping by the amount of effort expended in helping. ${ }^{2}$

As can be seen in Table 1, the pattern of correlations was consistent with the hypotheses. Sad attributions in the congruent stories were positively related to helping in the congruent condition, and reconciliations were positively related to helping in the incongruent condition. There were no significant relations between congruent attribution measures and helping in the incongruent condition, nor were there significant relations between reconciliations for the incongruent stories and helping in the congruent condition. Furthermore, the correlations between the sad attribution measure and helping in the congruent versus the incongruent conditions were significantly different, $Z=2.10, p<.05$, one-tailed; the correlations between the reconciliation measure and helping in the congruent versus the incongruent conditions were marginally different, $Z=1.55, p<.06$, onetailed. Finally, the cartoon story task was unrelated to helping in the congruent and the incongruent conditions, $r \mathrm{~s}=-.17$ and .10 , both $n s$. respectively.

Because we were concerned about violations of the normal distribution assumptions, we conducted analyses using arcsine transformations of the affective and the cognitive perspective-taking scores and reciprocal transformations of the helping measure; these analyses produced the same results. Also, the correlation between helping and the cartoon story task using the original coding scheme of Flavell et al. (1968) was nonsignificant. ${ }^{3}$

\section{Discussion}

In general, our findings supported the hypothesis that measures of social cognition are related to helping scores primarily when helping would be expected to be facilitated by the specific form of social cognition (Eisenberg, 1986; Kurdek, 1978). Specifically, children who made sad attributions in the congruent stories helped more in the congruent helping condition than did children who did not make sad attributions. In contrast, children who reconciled the conflicting cues in the incongruent stories helped more in the incongruent helping condition. As expected, scores on the

${ }^{2}$ A 2 (age) $\times 2$ (sex) $\times 2$ (helping condition) ANOVA on the helping composite revealed no significant effects.

${ }^{3}$ The relations between the social cognition measures and number of seconds turning, number of turns, and effort (as separate indices of helping) were also examined. In the congruent condition, sad attributions were significantly $(p<.05)$, positively related to number of turns, $r=.25$, and to both number of turns and number of seconds turning when both age and sex were partialed out, $r \mathrm{~s}=.39$ and .32 , respectively. In the incongruent condition, reconciliations were significantly, positively related to each helping index even when age and sex were both partialed out; $r$ s ranged from .27 to .35 . 
Table I

Relations and Partial Correlations Between Helping and Attributions and Reconciliations

\begin{tabular}{lcccc} 
Sociocognitive & $\begin{array}{c}\text { Congruent helping } \\
(\mathrm{n}=44)\end{array}$ & \multicolumn{2}{c}{$\begin{array}{c}\text { Incongruent } \\
\text { helping }(\mathrm{n}=45)\end{array}$} \\
measures & $r$ & Partial $r \mathrm{~s}$ & $r$ & Partial $r \mathrm{~s}$ \\
\hline Sad attributions & $.28^{*}$ & $.45^{* *}$ & -.17 & -.20 \\
Happy attributions & .11 & .11 & .14 & .11 \\
Reconciliations & .01 & .04 & $.34^{* *}$ & $.31^{*}$
\end{tabular}

Note. Attributions were coded from the congruent stories, and reconciliations were coded from the incongruent stories. Partial correlations (partial $r \mathrm{~s}$ ) were controlled for both sex and age.

$* p<.05$, one-tailed. $* * p<.01$, one-tailed.

measures derived from the congruent stories were not related to helping in the incongruent helping condition, and measures derived from the incongruent stories were not related to helping in the congruent helping condition. In addition, as expected, attributions and reasoning about affect were positively related to helping that required assessment of another's emotional state, whereas a cognitive perspective-taking task that did not focus on affective cues was unrelated to helping that required processing of affective cues (Denham, 1986; Eisenberg, 1986; Kurdek, 1978).

The present findings also suggest that there may be other cognitive abilities related to helping in addition to perspective taking. That is, the ability to reconcile conflicting affective cues, a cognitive ability beyond identifying the cues, was positively related to helping when the helping context included incongruent cues. This finding is consistent with other evidence of the importance of cognitive abilities other than perspective taking in social behaviors (e.g., Brady, Newcomb, \& Hartup, 1983; Chao, Knight, \& Dubro, 1986; Knight, Berning, Wilson, \& Chao, 1987; Knight, Bohlmeyer, Schneider, \& Harris, 1990). Past inconsistencies in the observed empirical relations between perspective taking and prosocial behaviors may be partially the result of variability in these additional cognitive prerequisites. For example, in some studies, a mismatch between the cognitive demands inherent in a prosocial behavior measure and those in a perspectivetaking measure may have resulted in underestimates of the expected pattern of the relation between these underlying constructs. Thus, it may be necessary to consider a range of potential cognitive prerequisites when hypothesizing about the role of cognitive development in prosocial behaviors.

Future investigations using the present approach are needed to validate the present findings in naturalistic settings. Furthermore, consideration of the relations of different sociocognitive abilities to prosocial behaviors (e.g., moral reasoning), abilities that have been hypothesized to relate significantly to helping, may be enhanced from using the present approach. For example, specific forms of moral reasoning (e.g., sympathetic-type reasoning, that is, reasoning pertaining to feeling concerned for another) may be positively associated with helping in situations that specifically require reasoning about affect (Eisenberg, 1986). Nevertheless, the findings of this study support the assertion that specific forms of helping require specific forms of social cognition.
In addition to matching cognitive demands, it also is necessary to consider motivational processes in explaining individual differences in helping (Eisenberg, 1986; Knight et al., 1987). That is, although a child may have the cognitive abilities underlying both a given social cognition measure and a helping measure, the child may not be motivated to use that cognitive skill in the helping situation; or, having used that cognitive skill in the helping situation and knowing that another is in need of help, the child may elect not to help. This motivational gap between knowledge and behavior no doubt accounts, in part, for the fact that sociocognitive abilities are at best only moderately associated with prosocial behavior. Nonetheless, sociocognitive skills, such as attributions and reasoning about affect, may frequently be a prerequisite for prosocial actions based on moral principles or empathy-based emotional responding (Eisenberg, 1986; Hoffman, 1984; Underwood \& Moore, 1982) and are therefore important for an understanding of altruistic behaviors.

The magnitude of the relations observed in this study may also have been attenuated by the reliability of the measures. As has been the case in previous research, the social cognition measures used in this study included few items. However, the reliabilities of two of the key social cognition measures (the sad attribution and the reconciliation measures) were quite adequate for 2- and 4-item scales. Furthermore, the consistent pattern of relations between social cognitions and helping suggests some reliability and construct validity. In previous studies, researchers have attempted to increase the reliability of indices of social cognition by aggregating several indices (Denham, 1986; Iannotti, 1985). However, the results of this study suggest that such an approach increases the magnitude and consistency of relations between social cognition measures and social behavior primarily when there is a match between the specific cognitive requirements of the multiple sociocognitive measures and the social behavior measures.

There were a few interesting age differences in responses to the affective attribution and helping measures. The age differences in affective attributions were consistent with previous evidence that young children avoid sad cues and prefer to report happy emotions and that older children explain affect more than do young children (Glasberg \& Aboud, 1982; Gnepp, 1983; Hoffner \& Badzinski, 1989; Iannotti, 1978; Kurdek \& Rogdon, 1975; Saarni, 1979). However, the age differences in helping in this study were very weak, perhaps because of the narrow age range sampled. It is possible that age differences in affective attributions and reasoning could account for age differences in helping (e.g., Radke-Yarrow, Zahn-Waxler, \& Chapman, 1983) in a wider age-range sample if the specific form of helping required these cognitive processes.

\section{References}

Brady, J. E., Newcomb, A. E, \& Hartup, W. W. (1983). Context and companion's behavior as determinant's of cooperation and competition in school-age children. Journal of Experimental Child Psychology, 36, 396-412. 
Chao, C.-C., Knight, G. P., \& Dubro, A. E. (1986). Information processing and age differences in social decision-making. Developmental Psychology, 22, 500-508.

Denham, S. (1986). Social cognition, prosocial behavior, and emotion in preschoolers: Contextual validation. Child Development, 57, 194-201.

Eisenberg, N. (1986). Altruistic emotion, cognition and behavior. Hillsdale, NJ: Erlbaum.

Eisenberg, N., \& Lennon, R. (1983). Sex differences in empathy and related capacities. Psychological Bulletin, 94, 100131.

Eisenberg, N., \& Miller, P. (1987). The relation of empathy to prosocial and related behaviors. Psychological Bulletin, $101,91-119$.

Flavell, J. H., Botkin, P., Fry, C., Wright, J., \& Jarvis, P. (1968). The development of role-taking and communication skills in children. New York: Wiley.

Glasberg, R., \& Aboud, E. (1982). Keeping one's distance from sadness: Children's self-reports of emotional experience. Developmental Psychology, 18, 287-293.

Gnepp, J. (1983). Children's social sensitivity: Inferring emotions from conflicting cues. Developmental Psychology, 19, 805-814.

Gnepp, J., McKee, E., \& Domanic, J. A. (1987). Children's understanding of situational information to infer emotion: Understanding emotionally equivocal situations. Developmental Psychology, 23, 114-123.

Hoffman, M. L. (1984). Empathy, its limitations, and its role in a comprehensive moral theory. In W. M. Kurtines \& J. L. Gewirtz (Eds.), Morality, moral behavior, and moral development (pp. 283-302). New York: Wiley.

Hoffner, C., \& Badzinski, D. M. (1989). Children's integration of facial and situational cues to emotion. Child Development, 60, 411-422.

Iannotti, R. J. (1978). Effect of role-taking experiences on role taking, empathy, altruism, and aggression. Developmental Psychology, 14, 119-124.

Iannotti, R. J. (1985). Naturalistic and structured assessments of prosocial behavior in preschool children: The influence of empathy and perspective taking. Developmental Psychology, $21,46-55$.

Knight, G. P., Berning, A. L., Wilson, S. L., \& Chao, C.-C. (1987). The effects of information-processing demands and social-situational factors on the social decision making of children. Journal of Experimental Child Psychology, 43, 244-259.
Knight, G. P., Bohlmeyer, E. M., Schneider, H., \& Harris, J. D. (1990). Age differences in sharing as a function of taskspecific cognitive prerequisites: Time estimation ability and a fixed-duration sharing task. Unpublished manuscript, Arizona State University, Tempe.

Kurdek, L. A. (1978). Perspective-taking as the cognitive basis of children's moral development: A review of the literature. Merrill-Palmer Quarterly, 24, 3-28.

Kurdek, L. A., \& Rogdon, M. M. (1975). Perceptual, cognitive, and affective perspective taking in kindergarten through sixth-grade children. Developmental Psychology, 11, 643650.

Liebert, R. M., \& Baron, R. A. (1972). Some immediate effects of televised violence on children's behavior. Developmental Psychology, 6, 469-475.

Mallick, S. K., \& McCandless, B. R. (1966). A study of catharsis of aggression. Journal of Personality and Social Psychology, 4, 591-596.

Nunnally, J. C. (1967). Psychometric theory. New York: McGraw-Hill.

Radke-Yarrow, M., Zahn-Waxler, C., \& Chapman, M. (1983). Prosocial dispositions and behavior. In P. Mussen (Series Ed.) \& E. M. Hetherington (Vol. Ed.), Manual of child psychology: Vol. 4. Socialization, personality, and social development (pp. 469-545). New York: Wiley.

Reichenbach, L., \& Masters, J. C. (1983). Children's use of expressive and contextual cues in judgments of emotion. Child Development, 54, 993-1004.

Saarni, C. (1979). Children's understanding of display rules for expressive behavior. Developmental Psychology, 15, 424429.

Shantz, C. U. (1975). The development of social cognition. In E. M. Hetherington (Ed.), Review of child development research (Vol. 5, pp. 257-323). Chicago: University of Chicago Press.

Strayer, J., \& Schroeder, M. (1989). Children's helping strategies: Influences of emotion, empathy, and age. In N. Eisenberg (Ed.), New directions for child development: Empathy and related emotional responses (pp. 85-105). San Francisco: Jossey-Bass.

Underwood, B., \& Moore, B. (1982). Perspective-taking and altruism. Psychological Bulletin, 91,143-173.

Submitted March 1990;

Revised May 1990;

Accepted June 1990. 